\title{
Genetic variation in the gravitropic response of maize roots to low temperatures
}

\author{
Andreas Hund \\ Institute of Plant, Animal and Agroecosystem Sciences, ETH Zurich, 8092 Zurich, Switzerland \\ Corresponding author: A. Hund, Email: andreas.hund@ipw.agrl.ethz.ch, Phone: +41 44632 3829, Fax: +41 44632 \\ 1143
}

Received on November 11, 2009; Accepted on May 23, 2010

\begin{abstract}
The distribution of roots in soil determines their acquisition of spatially varying resources. It may be altered by changing the response of roots to gravity. The aim of the study was to assess gravitropic set-point angles (GSAs) of maize (Zea mays L.) roots, their response to temperature and the feasibility to measure them in growth pouches. The GSAs of the primary, seminal and crown roots of a set of nine temperate inbred lines were measured. The lines were grown under controlled conditions in growth columns either at $15 / 13^{\circ} \mathrm{C}$ or $24 / 20^{\circ} \mathrm{C}$ (day/night) until the two-leaf stage (V2). The GSA was measured as the deviation of the initial $3 \mathrm{~cm}$ of root axis from the vertical zero. Low temperature resulted in a decrease in the GSAs of the crown roots by $10^{\circ}$, i.e. the roots oriented more vertically. The effect of the GSAs on the distribution of the roots was verified in wider columns using two extreme inbred lines. The proportion of roots in the upper $5 \mathrm{~cm}$ of the columns was $78 \%$ for the line S335 with the strongest tendency to horizontal root growth and only $39 \%$ for CM105 with almost vertical orientation of the roots. The differences in GSAs between these two genotypes were even more pronounced in growth pouches, thus proving the feasibility of this system for rapid screening. The results indicate that there is a huge genetic variability available to alter the growth direction of the seedling roots of maize. However, there was little effect of the temperature.
\end{abstract}

Keywords: corn, gravitropism, liminal angle, plagiogravitropism, root angle, Zea mays L.

Abbreviation: GSA, gravitropic set-point angle

\section{Introduction}

Variation in root architecture is essential for the adaptation of plants to target environments since it determines their efficiency in acquiring soil resources. One parameter determining root architecture and root occupancy of the soil is the gravitropic set-point angle (Digby and Firn 1995), sometimes also called 'liminal angle'. It is defined as the angle, at which an organ is maintained by gravitropism and is measured as the deviation from the vertical zero. Roots may grow vertical (orthogravitropic) oblique (plagiogravitropic) or horizontal (diagravitropic) in response to gravity. This response may be altered by environmental stimuli. Ge et al. (2000) illustrated the implication of changes in the GSA for the acquisition of phosphorus and/or water using the example of common bean (Phaseolus vulgaris L.). For this species, increased GSAs led to an increased uptake of phosphorus due to more intense foraging of the topsoil (Liao et al. 2001). For other species, decreased GSAs led to a better water acquisition due to deeper roots, for example in upland rice (Kato et al. 2006), sorghum (Tsuji et al. 2005), wheat (Manschadi et al. 2008) and maize (Hammer et al. 2009).

Apart from enhancing the acquisition of resources, greater GSAs may also facilitate the escape from low subsoil temperatures. It was observed already in the late $19^{\text {th }}$ century that maize roots grew more horizontally early in the season than later (Three references cited by Onderdon and Ketcheso, 1973). While the authors of these early studies assumed that the temperature gradient was responsible for this effect, later studies identified temperature per se as the cause. GSAs were largest at about $18^{\circ} \mathrm{C}$. They decreased with increasing temperatures from 18 to $36^{\circ} \mathrm{C}$ (Mosher and Miller 1972, Onderdon and Ketcheso 1973) and also with decreasing temperatures from 17 to $10^{\circ} \mathrm{C}$ (Onderdon and Ketcheso 1973). The temperatures during the early developmental phase, when the

Hund A 2010 Genetic variation in the gravitropic response of maize roots to low temperatures. Plant Root 4: 22-30. doi:10.3117/plantroot.4.22

Copyrights 2010, Plant Root (JSRR), www.plantroot.org 
roots were less than $10 \mathrm{~cm}$ long, determined their later trajectory in the field (Tardieu and Pellerin 1991): the horizontal spread of these roots decreased exponentially with increasing soil temperature. This temperature effect may explain the decrease in the GSAs of crown roots from higher internodes, which develop in warmer soil later in the season (Araki et al. 2000, Kaeriyama and Yamazaki 1983, Tardieu and Pellerin 1990).

But are there genetic differences in the GSAs of maize roots and their response to temperature? There is not much information available since experiments were usually conducted with one genotype, only. Distinct phenotypes for nodal root angle were found by Irwin et al. (1985) for 11 hybrids. Quantitative trait loci for root angles were mapped in the context of lodging resistance of maize (Barriere et al. 2001, Guingo et al. 1998) and flooding tolerance of a maize $\times$ teosinte cross (Omori and Mano 2007). Furthermore, two maize mutants showed pleiotropic effects between branching pattern and gravitropic response (Taramino et al. 2007, Woll et al. 2005).

The lack of information about genetic differences for root architecture, including GSAs, may be attributed to the difficulty to assess the trait. This situation is rapidly changing: non-invasive imaging techniques open new possibilities for root phenotyping of large germplasm sets. Imaging is becoming more and more popular since the computer processing power, the resolution of imaging sensors and affordable disc space increased dramatically during the last decades. In parallel, two dimensional growth systems were developed allowing for a non-destructive imaging of the roots. For example, the distribution of roots in two dimensions was studied in gel chambers (Bengough et al. 2004), root observation chambers (Manschadi et al. 2006), on germination paper in pouches (Hund et al. 2009), using X-ray absorption (Pierret et al. 2003) or light transmission (Garrigues et al. 2006). Some of these systems with an image acquisition time in the order of minutes allow for enough throughput. For example, growth pouches in combination with digital image analysis allowed to map quantitative trait loci for root elongation (Ruta et al. 2010, Trachsel et al. 2009).

Sampling roots of temperate maize inbred lines in a cold-tolerance study (Hund et al. 2008), I observed differences in GSAs. Some roots did not grow vertically into the growth column but circled along its surface, sometimes even growing upwards. My objectives were, accordingly, to evaluate the GSAs of maize roots and their response to temperature. Additionally, I aimed to find out if GSAs could be determined equally well in growth pouches, which would allow for rapid screening.

\section{Materials and Methods}

\section{Experiment 1 in narrow columns}

A set of nine inbred lines, D171, CM105, ETHDeL3, ETHFlH1, ETHF1L8, Lo 964, Lo 1016, D167 and S335, was evaluated in narrow growth columns (5.6 $\mathrm{cm}$ in diameter and $50 \mathrm{~cm}$ high) at low $15 / 13^{\circ} \mathrm{C}$ (day/night) and high $24 / 20^{\circ} \mathrm{C}$ (day/night) air and soil temperature. For details concerning the lines see Hund et al. (2007). The lines were grown in growth chambers (PGW36, Conviron, Winnipeg, Canada) at a $12 \mathrm{~h}$ photo- and thermoperiod, 60/70\% (day/night) relative air humidity and $500 \mu \mathrm{mol} \mathrm{m} \mathrm{m}^{-2} \mathrm{~s}^{-1}$ photosynthetic photon flux density (PPFD). The growth substrate was a mixture of quartz sand (particle size 0.08 to $0.2 \mathrm{~mm}$ ) and $5 \% \mathrm{w} / \mathrm{w}$ vermiculite powder (Vermex Pulver E, Vermica AG, Bözen, Switzerland) with a volumetric content of $15 \%$ modified Hoagland solution (Hund et al. 2007). Moist substrate was packed into the growth columns to a bulk density of $1.25 \mathrm{Mg} \mathrm{m}^{-3}$; after planting, the substrate was covered with a $1-\mathrm{cm}$ isolation layer of Perlit $\left(\mathrm{PePe}^{\circledR}\right.$ Pflanzen Perlit, Otto Hauenstein Samen AG, Rafz-BiberistLandquart-Orbe, Switzerland). Seeds were surface-sterilised for $12 \mathrm{~min}$ with $2.5 \% \mathrm{NaOCl}$, pre-germinated at $25^{\circ} \mathrm{C}$ and planted at a depth of $2 \mathrm{~cm}$ with the primary root pointing downwards. Once the coleoptile had reached a length of $\sim 1 \mathrm{~cm}$, the growth columns were covered with aluminium foil to prevent warming of the upper zone of the substrate due to the light. The soil temperature was measured at $1 \mathrm{~cm}$ (in the isolation layer), $5 \mathrm{~cm}$ and $15 \mathrm{~cm}$ depth. It was constant throughout the substrate and about $1{ }^{\circ} \mathrm{C}$ higher in the isolation layer.

\section{Measurements}

The genotypes were harvested when more than half the plants had reached the two-leaf (V2) stage. After removing the root system from the growth columns, the roots were rigid enough to allow measurement of their initial angle. For each root, i.e. the primary root, all seminal roots and all crown roots of the first and second shoot internodes, the initial gravitropic set-point angle was measured. The distances (about 3 $\mathrm{cm}$ ) between the point of root emergence and the point, at which it touched the wall of the tube were used to calculate the initial GSA, further just termed GSA. It was calculated as the arctangent of the ratio between the horizontal distance (Fig. 1, a) and vertical distance (Fig. 1, b). 


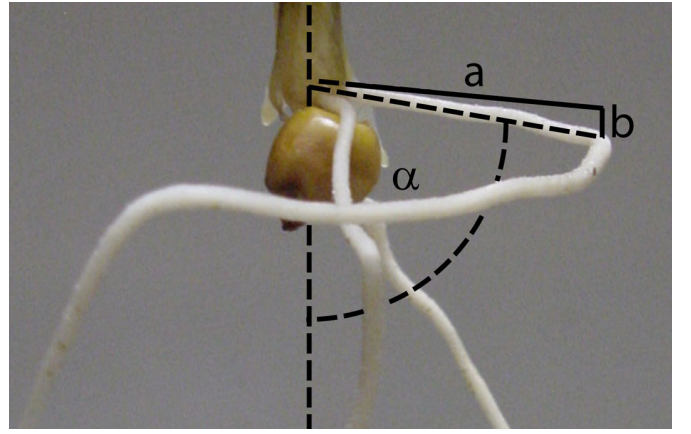

Fig. 1 Gravitropic set-point angles $(\alpha)$, of the inbred line S335 in narrow growth columns was measured as the deviation from the vertical zero as an arctangent of the ratio of distance $a$ to $b$.

\section{Experimental design and statistics}

The experimental design was a randomised complete block design with two growth chamber replications at both low and high temperatures. Each replication consisted of four blocks, each containing a whole set of genotypes. The experimental unit within block and replication was one growth column with one plant. Thus, the experimental design was:

$y_{i j k l m}=g_{i}+a_{j}+t_{k}+g a_{i j}+g t_{i k}+a t_{j k}+g a t_{i j k} \mid r_{l}+b_{l m}+p_{i l m}+\varepsilon_{i j k l m}$

where the GSA of each individual root $y_{i j k l m}$ depended on the root type and internode it emerged from $a_{j}(j=$ primary root, seminal roots and crown roots from the first and second internode), inbred line $g_{i}(i=1, \ldots, 9)$, temperature $t_{k}\left(k=15 / 13\right.$ or $24 / 20^{\circ} \mathrm{C}$ day/night $)$ and their interactions. Each of the four root categories was nested within growth chamber run $r_{l}(l=1, \ldots, 4$; two runs per temperature), complete randomized blocks within growth chamber run $b_{l m}(m=1, \ldots, 4)$, individual plant per genotype within complete block $p_{i l m}$ and the random error $\varepsilon_{i j k l m}$. Random effects are those to the right of the vertical line in Equation 1. Analysis of variance was carried out with the 'ASReml-R' package in $\mathrm{R}$ (Butler 2006).

I aimed to determine whether the GSAs of root types that develop early can be used to predict the GSAs of root types that develop later. Therefore, multiple mixed linear models based on the best linear unbiased predictors derived from equation 1 were fitted for each pair of root types:

$y_{i k}=a+t_{k}+a t_{k} \mid g_{i}+\varepsilon_{i k}$

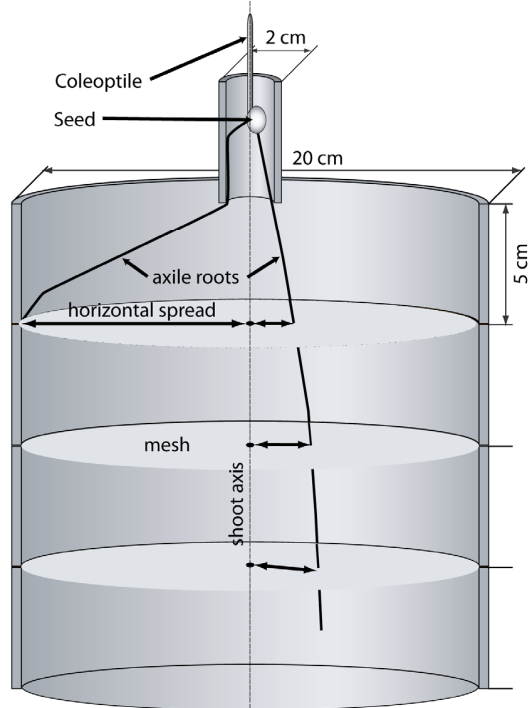

Fig. 2 Wide growth columns to measure the vertical and horizontal distribution of roots of contrasting inbred lines S335 and CM105. Plants were placed in a $2-\mathrm{cm}$ cylinder to force the roots to grow vertically. Roots grew in their original direction when entering the wide column with a diameter of $20 \mathrm{~cm}$. The positions at the mesh where the roots grew into the next sections were marked. The distance between the central imaginary shoot axis and the marked position presented the horizontal spread.

where $y_{i k}$ is the GSA of a later developing root type (e.g. seminal roots or crown roots from the first and second internode) depending on the GSAs of an earlier developing root type $a$ (e.g. primary root, seminal roots or crown roots from the first internode), the temperature $t_{k}\left(k=15 / 13\right.$ or $24 / 20^{\circ} \mathrm{C}$ day/night $)$, the interaction $a t_{k}$ and the random genotype $g_{i}(i=1, \ldots, 9)$. The intercept was set to $45^{\circ}$, by subtracting the trait values of the earlier root type by 45 .

\section{Experiment 2 in wide columns}

I aimed to determine whether a large initial GSA would lead to a significant change in the distribution of roots in soil. For this purpose two genotypes with contrasting GSAs (CM105 and S335) were grown in wider columns with, $20 \mathrm{~cm}$ in diameter and $20 \mathrm{~cm}$ high. Four plants per genotype (one per column) were grown to the V2 stage at $15 / 13^{\circ} \mathrm{C}$. The same substrate and environmental conditions were used as in experiment 1 . The columns were divided vertically into $5-\mathrm{cm}$ sections separated by a $2-\mathrm{mm}$ mesh (Fig. 2) to allow recording of the horizontal spread of the axile roots. At harvest, the distances between the radial axis (shoot axis) and the point at which the axile roots 
passed through the mesh into the next column section were measured. After recording this horizontal spread, the roots in each column section were harvested and cleaned under running tap water. The root length within each column section was determined by digital image analysis: roots were spread in a tray in a thin layer of water and scanned with a scanner equipped with a top light (Epson, Expression 1640 XL, Epson America, Inc., USA) to acquire 8 bit images at a resolution of 23.7 dots per $\mathrm{mm}$ ( $600 \mathrm{dpi})$. The images were subsequently analyzed with WinRHIZO 2003b (Regent Instruments, Montreal, QC, Canada) to measure the length of the roots. The debris removal filter was set to remove objects with an area smaller than $0.005 \mathrm{~cm}^{2}$ and a length/width ratio lower than 5 .

\section{Experiment 3 in growth pouches}

Excavating roots from soil is laborious and does not allow for sufficient throughput for the screening of larger populations. Therefore, I wanted to know if the results obtained in sand could be reproduced in growth pouches, described by Hund et al. (2009). The two genotypes CM105 and S335 of Experiment 2, were evaluated in these pouches on blotting paper $(21 \times 29.5$ $\mathrm{cm}$; Anchor Paper, St. Paul, MN, USA). A total of nine plants per genotype grew under $24 / 20^{\circ} \mathrm{C}$ day/night until 10 days after germination. Their root systems were scanned using a Hewlett Packard Scanjet 4670 "See Thru Vertical Scanner" (Hewlett-Packard, Palo Alto, CA, USA). The GSAs of the seminal, primary and crown roots were measured using the "Ruler" tool of Photoshop (Photoshop CS3 extended, Adobe Systems Inc., San Jose, CA, USA). The initial GSA was measured by drawing a line (trace) from the origin of the root to the point where the roots changed the direction significantly. This endpoint was chosen in a way that the distance between the trace and the root was never larger than 1 $\mathrm{cm}$ (c.f. Fig. 5, arrows). The mixed linear model to determine the difference in GSAs among root types and between genotypes was calculated with ASReml-R was:

$y_{i j k l}=g_{i}+a_{j}+g a_{i j} \mid r_{k}+b_{i k}+p_{i k l}+\varepsilon_{i j k l}$

where the trait value of each individual root $y_{i j k l}$ depends on the root type $a_{j}(j=1, \ldots, 3)$, the inbred line $g_{i}(i=\mathrm{CM} 105$ or S335) and their interactions. The root types were nested within growth chamber run $r_{k}$ $(k=1, \ldots, 3)$, randomly distributed genotypes within growth chamber run $b_{i k}$ and individual plants per genotype within growth chamber run $p_{i k l} \quad(l=1, \ldots, 3)$.

\section{Results}

Inbred lines classified according to vertical and horizontal rooting

Genotypes were classified according to shallow and deep rooting, independent of temperature. An example of the orientation of the crown roots of inbred line S335 is shown in Fig. 1. Significant effects on the GSAs were detected for most explaining factors and their interactions. Only the inbred line-by-temperature interaction and the three-way interaction among the temperature, inbred line and root type was not significant (Table 1). Averaged over root types, the genotypes with the most vertically oriented GSAs were D171, Lo1016 and CM105, the genotypes with the most horizontally oriented GSAs were ETHDeL3, ETHFIL8 and S335. The GSAs of the seminal roots showed the largest variation among genotypes $\left(30^{\circ}\right.$ to $70^{\circ}$ ) followed by those of the primary root, $\left(5^{\circ}\right.$ to $\left.30^{\circ}\right)$, and the crown roots $\left(40^{\circ}\right.$ to $\left.60^{\circ}\right)$.

Low temperature resulted in a more vertical orientation of crown roots by $10^{\circ}$

In general the primary roots grew more vertically with

Table 1 Anova results of the effect of the inbred line (Line), temperature regime (Temp) and root type (Root; primary, seminal, crown 1 and crown 2) on the gravitropic set-point angle in narrow growth columns

\begin{tabular}{llccc}
\hline & Df. & Sum of Sq. & Wald statistic & $\mathrm{P}^{\text {a }}$ (Chisq) \\
\hline Line & 8 & 17733 & 95 & $* * *$ \\
Temp & 1 & 13067 & 70 & $* * *$ \\
Root & 3 & 63368 & 340 & $* * *$ \\
Line: Temp & 8 & 2532 & 14 & $*$ \\
Line: Root & 24 & 12583 & 67 & $* *$ \\
Temp: Root & 3 & 4109 & 22 & $*$ \\
Line:Temp: Root & 20 & 5668 & 30 & \\
\hline
\end{tabular}

${ }^{\mathrm{a}}$ Significance level at $\mathrm{p}<0.1($.$) and 0.001(* * *)$. 
Table 2 Gravitropic set-point anlges in narrow growth columns as dependent on temperature (Temp.), inbred line and root type

\begin{tabular}{|c|c|c|c|c|}
\hline \multirow{2}{*}{ Inbred line } & \multicolumn{4}{|c|}{ Gravitropic set-point angle $\left(^{\circ}\right)$} \\
\hline & $\operatorname{Pr}^{\mathrm{a}}$ & $\mathrm{Se}^{\mathrm{b}}$ & $\mathrm{Cr} 1^{\mathrm{c}}$ & $\mathrm{Cr} 2^{\mathrm{d}}$ \\
\hline D171 & 13.7 & 28.3 & 45.7 & 38.5 \\
\hline Lo 1016 & 5.4 & 42.8 & 42.4 & 40.0 \\
\hline CM105 & 23.6 & 37.0 & 42.2 & $\mathrm{NA}^{\mathrm{e}}$ \\
\hline ETHFlH1 & 16.3 & 47.3 & 39.8 & NA \\
\hline Lo 964 & 15.5 & 42.9 & 51.3 & 43.1 \\
\hline D167 & 24.6 & 52.9 & 51.1 & NA \\
\hline ETHDeL3 & 24.8 & 62.8 & 39.9 & 50.6 \\
\hline ETHFIL8 & 32.2 & 47.2 & 53.2 & 49.1 \\
\hline S335 & 25.4 & 71.6 & 58.8 & NA \\
\hline avsed $^{f}$ & 6.6 & & & \\
\hline \multicolumn{5}{|l|}{ Temp. $\left({ }^{\circ} \mathrm{C}\right)^{\mathrm{g}}$} \\
\hline $15 / 13^{c}$ & 12.7 & 48.9 & 42.3 & 43.2 \\
\hline $24 / 20$ & 27.6 & 47.3 & 52.0 & 53.4 \\
\hline avsed & 3.8 & & & \\
\hline Mean & 20.2 & 48.1 & 47.2 & 44.3 \\
\hline
\end{tabular}

${ }^{a}$ primary root

${ }^{b}$ seminal root

${ }^{c}$ crown root from the first shoot internode

d crown root from the second shoot internode

${ }^{\mathrm{e}}$ not estimated since low number of plants advanced to $\mathrm{Cr} 2$

${ }^{f}$ average standard error of the difference

${ }^{\mathrm{g}}$ temperature day/night

mean GSAs of about $20^{\circ}$, while the successive developing seminal and crown roots grew more horizontally with mean GSAs between $44^{\circ}$ and $48^{\circ}$ (Table 2). Surprisingly, low temperature resulted in a more vertical orientation of primary axile roots (about $15^{\circ}$ ) and crown roots (about $\left.10^{\circ}\right)($ Table 2). The responses of GSAs of the embryonic primary and seminal roots to temperature must be considered with caution since these roots may have established at slightly higher temperature. The reason for this is that the final soil temperature was adjusted by covering the column with aluminium foil after the coleoptile emerged. For example, in the low temperature treatment, the temperature at 1 (in the Perlite), 5 and $15 \mathrm{~cm}$ column depth was about 19,17 and $16^{\circ} \mathrm{C}$, respectively, before covering the tubes and 16,15 and $15^{\circ} \mathrm{C}$ thereafter.

The GSAs of seminal and early crown roots correlated with the GSAs of crown roots from the second internode

Can GSAs of early internodes be used to predict GSAs of later internodes and does temperature play a role? Using equation 2 , the angles of the primary roots, which tended to grow vertically, could not be used to predict GSAs of later root types (data not shown). However, for other root types, predictions were possible (Table 3,a). The GSAs of the crown roots from the second internode could be predicted by those of the seminal roots (slope of 0.97 ) and the crown roots from the first internode (slope of 1.41). Temperature did not influence this covariance since no interaction was found between temperature and GSA (data not shown). Thus, the interaction terms $\left(a t_{k}\right)$ were dropped from the models. Temperature affected the intercept of the growth angles for those models where the seminal roots were the explaining variable (Table 3,t). Optimal temperature resulted in an estimated increase in the root angles of the crown roots of about $10^{\circ}$.

Variability in GSAs resulted in different soil exploration of two contrasting genotypes

The GSAs for the contrasting inbred lines, CM105 with a more vertical root orientation and S335 with a more horizontal root orientation, are shown in Fig. 3. The GSAs of the seminal and crown roots of S335 were much larger as those of CM105. The effect of the differences in GSAs on the distribution of roots in soil

Table 3 Linear mixed model (equation 2) to predict GSAs of later developing root types as dependent on the temperature and GSAs of earlier developing root types

\begin{tabular}{llrrrrrr}
\hline & & \multicolumn{2}{c}{ Cr 1 vs. Se } & \multicolumn{2}{c}{ Cr 2 vs. Se } & \multicolumn{2}{c}{ Cr 2 vs. Cr 1 } \\
\cline { 3 - 8 } & & estimate & $\mathrm{p}^{\text {a }}$ & estimate & $\mathrm{p}$ & estimate & $\mathrm{p}$ \\
\hline Intercept & $\left(\text { at } 45^{\circ}\right)^{\mathrm{b}}$ & 41.19 & $* * *$ & 38.44 & $* * *$ & 45.98 & $* * *$ \\
Root angle & $(a)$ & 0.29 & $*$ & 0.97 & $* *$ & 1.41 & $* *$ \\
Optimal Temp. & $(t)$ & 9.45 & $*$ & 11.78 & $*$ & -0.94 & $\mathrm{~ns}$ \\
\hline
\end{tabular}

For abbreviations of root types see Table 2 .

${ }^{\mathrm{a}}$ significance level at $\mathrm{p}<0.1(),. 0.05(*), 0.01(* *)$ and $0.001(* * *)$.

${ }^{\mathrm{b}}$ The intercept was set at $45^{\circ}$. 


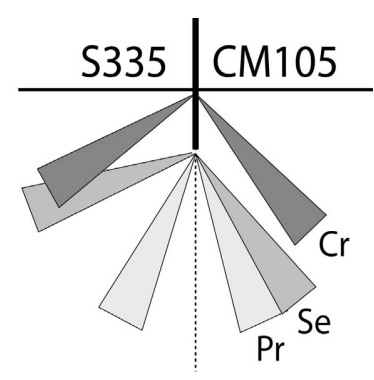

Fig. 3 Gravitropic set-point angles (GSA) of contrasting inbred lines S335 and CM105 in narrow growth columns. Shaded areas indicate average GSAs including 95\% confidence intervals of the primary ( $\mathrm{Pr})$, seminal $(\mathrm{Se})$ and crown $(\mathrm{Cr})$ roots of the first internode.

Table 4 Best linear unbiased estimates (equation 3 ) of gravitropic set-point anlges (GSA) measured in growth pouches as dependent on inbred line and root type

\begin{tabular}{cccc}
\hline & \multicolumn{3}{c}{ Factors } \\
\cline { 2 - 4 } & Line & Root & Line:Root \\
\hline ANOVA & $* * *$ & $* * *$ & ns \\
\hline
\end{tabular}

\begin{tabular}{lccc}
\hline & \multicolumn{3}{c}{ GSA of root type $\left(^{\circ}\right)$} \\
\cline { 2 - 4 } Inbred Line & $\operatorname{Pr}^{\mathrm{a}}$ & $\mathrm{Se}^{\mathrm{b}}$ & $\mathrm{Cr}^{\mathrm{c}}$ \\
\hline CM105 & 14.3 & 29.0 & 43.4 \\
S335 & 19.4 & 53.5 & 68.2 \\
avsed $^{\mathrm{d}}$ & 8.2 & & \\
\hline
\end{tabular}

a primary root
${ }^{b}$ seminal root
${ }^{c}$ crown root
${ }^{d}$ average standard error of the difference

was evaluated using the wide growth columns (Experiment 2). The axile roots of S335 spread in a much more horizontal direction and, consequently, did not reach the lowest 15 to $20-\mathrm{cm}$ section of the column (Fig. 4a). By contrast, the axile roots of CM105 grew much more vertically and reached the 15 to $20-\mathrm{cm}$ section of the columns. This difference in vertical root distribution is corroborated by the relative distribution of the roots (Fig. 4b). The inbred line S335 had twice as many roots in the 0 to $5 \mathrm{~cm}$ section compared to CM105. This changed in the successive column sections where CM105 had at least twice as many roots.

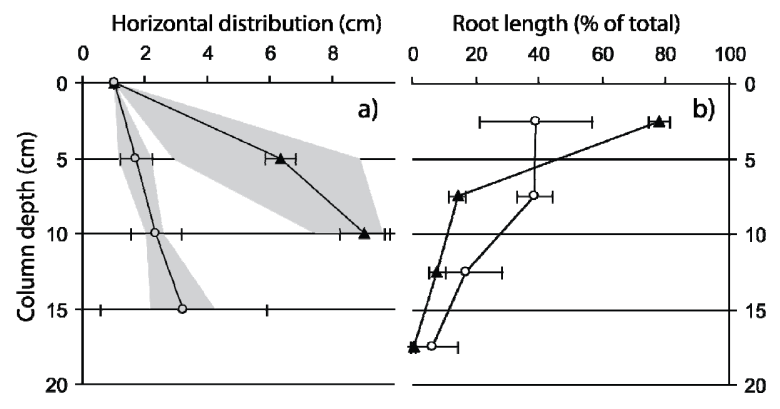

Fig. 4 Root distribution of two contrasting genotypes in wide growth columns: S335 (triangles) with more horizontal rooting; CM105 (circles) with more vertical rooting. Distance from the shoot axis, at which axile roots passed into the next column sections (a; horizontal spread, $c f$. Fig. 2) and distribution of root length with column depth as percentage of total root length (b). Shaded areas indicate the average maximum and minimum horizontal spread of the axile roots. Error bars show one standard deviation.

\section{Growth pouches are suitable for assessing GSAs}

The differences in the GSA of CM105 and S335 were verified in growth pouches. The lines differed with respect to the GSA of their seminal and crown roots (Table 4). Compared to GSAs measured in the narrow columns, the differences between the genotypes were even more pronounced. At $24 / 20^{\circ} \mathrm{C}$ (day/night) in narrow columns, the differences between the genotypes were $19^{\circ}$ for the seminal roots and $6^{\circ}$ for the crown roots of the first whorl. In growth pouches these differences were around $30^{\circ}$ for both root types. Two root systems of CM105 and S335, each, are shown in Fig. 5. The magnified part of the image illustrates how GSAs were measured.

The primary roots of the two S335 plants in Fig. 5 show a plagiogravitropic response changing from an almost vertical orientation to a more horizontal orientation. Since only the initial GSAs were measured, this later change was not recorded. Taking it into account may have resulted in pronounced differences also between the GSAs of the primary roots of the two genotypes.

\section{Discussion}

The GSAs of the inbred lines differed strongly, leading to pronounced differences in the distribution of roots in the wider columns. If classified according to the simplified root system shapes illustrated by Hammer et al. (2009), the inbred line CM105 had a more elliptical root system, while S335 had a standard circular root system. According to Hammer et al. (2009), the more elliptical, compact root system may reflect the root system of modern varieties adapted to 


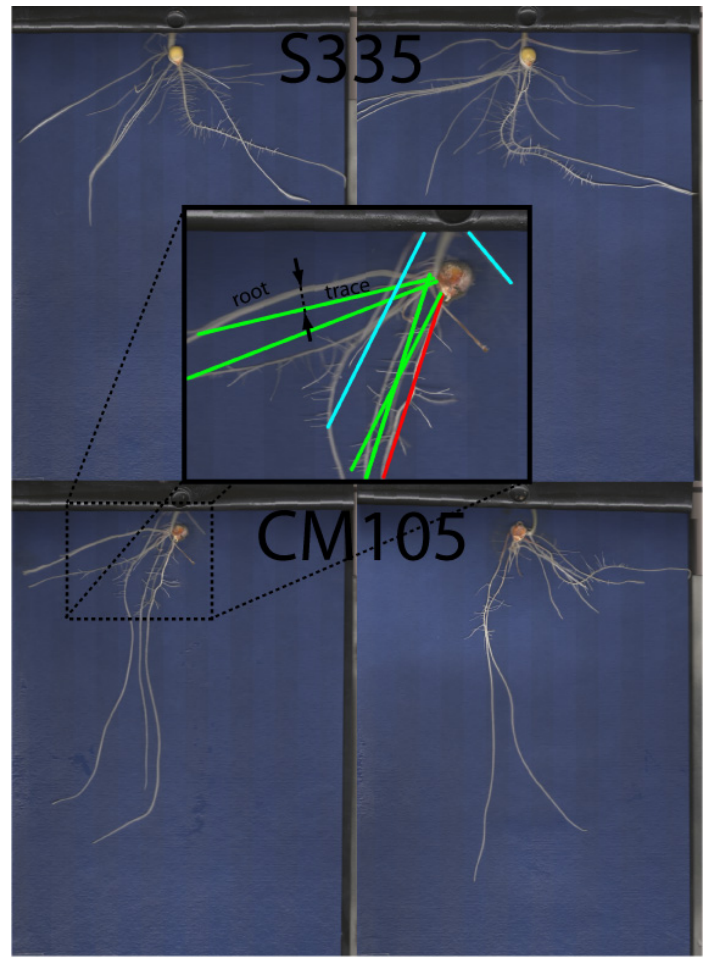

Fig. 5 Examples of the root system of S335 and CM105 (two plants each) grown in growth pouches. The magnified area illustrates the measurement of the GSAs of the primary root (red), seminal roots (green) and crown roots (blue). The roots were traced in a way, that the distance between the root and the trace (see arrows) was never larger than $1 \mathrm{~cm}$.

high plant density. However, there are several reasons why this may be an over-simplification. In particular in cool or phosphorus-deficient soil, more horizontal orientation of some roots may be of greater benefit. The avoidance of low subsoil temperature by increased GSAs is well documented for maize (Mosher and Miller, 1972; Onderdon and Ketcheso, 1973; Tardieu and Pellerin 1991). However, this type of response was not verified in the present set of inbred lines. On the contrary, the crown roots grew in a slightly more vertical direction. Similar effects were observed by Onderdon and Ketcheso (1973) where the GSAs were largest at $17^{\circ} \mathrm{C}$ and lower when plants were grown at lower temperature. The initial GSAs were measured between 0 and about $3 \mathrm{~cm}$ from the shoot base in a substrate with uniform temperature (due to the isolation layer of Perlit and the coverage with aluminium foil). Therefore, it may be argued, that the roots would have responded if there had been a temperature gradient in the substrate. However, according to studies under controlled conditions, the temperature per se rather than thermotropism is responsible for altering the GSA of roots in soil (Mosher and Miller, 1972; Sheppard and Miller, 1977).

Compared with the GSAs reported in older literature, the GSAs of the modern inbred lines used here, showed a striking difference: The primary root of modern inbred lines oriented almost vertical, while the primary (and seminal roots) of older genotypes grew almost horizontally, i.e. were plagiogravitropic or even diagravitropic (Feldman and Briggs 1987, Kisselbach 1999, Mosher and Miller 1972, Onderdon and Ketcheso 1973, Scott and Wilkins 1969, Suzuki and Fujii 1978, Weaver 1925). It is tempting to speculate that the more vertical orientation of modern inbred lines reflects breeders' selection during the last 30 years as suggested by Hammer et al. (2009). This raises the question as to whether roots of modern inbred lines have lost their ability to benefit from warming of the superficial soil layer in spring by more horizontal rooting.

One problem of testing the adaptive value of a more horizontally oriented seedling root system is the effect of soil temperature on the shoot apex of maize seedlings (Hund et al. 2008). Low apex temperatures cause a strong decrease in the photosynthetic efficiency of some lines, e.g. CM105. In order to test the beneficial effect of shallow rooting independent of this temperature effect on photosynthesis, one solution is to develop near-isogenic lines for this trait.

Another problem is that the initial GSAs may not be sufficient to characterize genotypes according to the distribution of their roots in soil. For example, plagiogravitropic behaviour of the primary root becomes obvious only after the roots grow to a considerable length in the soil (Nakamoto 1994). This behaviour could also be observed for the primary root of S335 in the growth pouches (Fig. 5). The plagiogravitropic response of these roots in the pouches may be quantified in using adequate software allowing to measure root trajectories. Such software is available for simpler root system, such as the one of Arabidopsis thaliana L. (Armengaud et al. 2009). Thus, growth pouches are feasible to measure both initial GSAs and successive gravitropic responses of the roots.

My major concern was that scattered light in the pouch may lead to a decrease in the GSAs (Feldman and Briggs, 1987). However, the GSAs deviated to an even greater extent from the vertical as in sand, and the effect of scattered light therefore seemed to be marginal. The feasibility of growth pouches to measure GSAs is also supported by Bonser et al. (1996) using them successfully to assess the response of GSAs of basal roots of common bean to phosphorus. Growth pouches or gel chambers are among the phenotyping systems with the highest throughput and are probably first choice for selection experiments or 
QTL mapping approaches. More elegant methods to assess the root system in undisturbed soil, such as magnetic resonance tomography (MRI) (Van As 2007) or x-ray computer tomography (Gregory et al. 2003) have the disadvantage that they lack throughput. For example, the throughput of partly automated MRI screening systems is expected to be 10-15 individuals per day (Jahnke et al. 2009). For larger plants, excavating the roots in the field may be efficient to assess this trait. Working with larger plants would allow measuring the dynamics of the change in GSAs across successively developing internodes. The initial GSAs of maize decrease with increasing internode (Araki et al. 2000) but there may be differences among genotypes as indicated by the results presented here: Roots emerging from the first shoot internode may already exhibited a strong vertical orientation, as shown for CM105.

\section{Conclusion}

There was great variability in the GSAs among the tested inbred lines ranging from vertical to almost horizontal. The GSAs did not increase at low temperature suggesting that most studied genotypes would not be able to benefit from soil warming in spring. Given the importance of the GSAs for the acquisition of resources from soil, we need more insight into their genetic control. Growth pouches proved feasible for measuring GSAs at similar precision as in a more natural sand substrate. The comparably high throughput of these pouches enables the selection for GSAs or mapping of quantitative trait loci controlling them. This in turn enables us to elucidate the significance of GSAs for the adaption of plants to cool soil in spring.

\section{Acknowledgements}

I would like to thank Prof. Dr. Peter Stamp for supporting this project, Marcia Schoenberg for linguistic corrections, and Lilly Stamp for her help with analysing the root systems.

\section{References}

Araki H, Hirayama M, Hirasawa H, Iijima M 2000 Which roots penetrate the deepest in rice and maize root systems? Plant Prod. Sci. 3: 281-288.

Armengaud P, Zambaux K, Hills A, Sulpice R, Pattison RJ, Blatt MR, Amtmann A 2009 EZ-Rhizo: integrated software for the fast and accurate measurement of root system architecture. Plant J. 57: 945-956.

Barriere Y, Gibelin C, Argillier O, Mechin V 2001 Genetic analysis in recombinant inbred lines of early dent forage maize. I - QTL mapping for yield, earliness, starch and crude protein contents from per se value and top cross experiments. Maydica 46: 253-266.
Bengough AG, Gordon DC, Al-Menaie H, Ellis RP, Allan D, Keith R, Thomas WTB, Forster BP 2004 Gel observation chamber for rapid screening of root traits in cereal seedlings. Plant Soil 262: 63-70.

Bonser AM, Lynch J, Snapp S 1996 Effect of phosphorus deficiency on growth angle of basal roots in Phaseolus vulgaris. New Phytol. 132: 281-288.

Butler D 2006 asreml: asreml() fits the linear mixed mode. R package version 2.00 .

Digby J, Firn RD 1995 The gravitropic set-point angle (GSA): The identification of an important developmentally controlled variable governing plant architecture. Plant Cell Environ. 18: 1434-1440.

Feldman LJ, Briggs WR 1987 Light-regulated gravitropism in seedling roots of maize. Plant Physiol. 83: 241-243.

Garrigues E, Doussan C, Pierret A 2006 Water uptake by plant roots: I - Formation and propagation of a water extraction front in mature root systems as evidenced by $2 \mathrm{D}$ light transmission imaging. Plant Soil 283: 83-98.

Ge Z, Rubio G, Lynch JP 2000 The importance of root gravitropism for inter-root competition and phosphorus acquisition efficiency: results from a geometric simulation model. Plant Soil 218: 159-171.

Gregory PJ, Hutchison DJ, Read DB, Jenneson PM, Gilboy WB, Morton EJ 2003 Non-invasive imaging of roots with high resolution X-ray micro-tomography. Plant Soil 255: 351-359.

Guingo A, Hébert Y, Charcosset A 1998 Genetic analysis of root traits in maize. Agronomie 18: 225-235.

Hammer GL, Dong Z, McLean G, Doherty A, Messina C, Schussler J, Zinselmeier C, Paszkiewicz S, Cooper M 2009 Can changes in canopy and/or root system architecture explain historical maize yield trends in the U.S. Corn Belt? Crop Sci. 49: 299-312.

Hund A, Fracheboud Y, Soldati A, Stamp P 2008 Cold tolerance of maize seedlings as determined by root morphology and photosynthetic traits. Eur. J. Agron. 28: 178-185.

Hund A, Richner W, Soldati A, Fracheboud Y, Stamp P 2007 Root morphology and photosynthetic performance of maize inbred lines at low temperature. Eur. J. Agron. 27: 52-61.

Hund A, Trachsel S, Stamp P 2009 Growth of axile and lateral roots of maize: I development of a phenotyping platform. Plant Soil 325: 335-349.

Irwin RL, Johnson WC, Elkins CB 1985 Root systems vary among corn hybrids. Highlights Agric. Res. 32: 16.

Jahnke S, Menzel MI, van Dusschoten D, Roeb GW, Buhler J, Minwuyelet S, Blumler P, Temperton VM, Hombach T, Streun M, Beer S, Khodaverdi M, Ziemons K, Coenen HH, Schurr U 2009 Combined MRI-PET dissects dynamic changes in plant structures and functions. Plant J. 59: 634-644.

Kaeriyama N, Yamazaki K 1983 The development of rooting zone in soil in relation to the growth direction and the elongation rate of the primary roots in corn plants. Jpn. J. Crop Sci. 52: 508-514.

Kato Y, Abe J, Kamoshita A, Yamagishi J 2006 Genotypic variation in root growth angle in rice (Oryza sativa L.) and its association with deep root development in upland fields with different water regimes. Plant Soil 287: 117-129.

Kisselbach TA 1999 The structure and reproduction of corn. 50th anniversary edition. Cold Spring Harbor Labporatory Press, New York, USA.

Liao H, Rubio G, Yan XL, Cao AQ, Brown KM, Lynch JP 2001 Effect of phosphorus availability on basal root 
shallowness in common bean. Plant Soil 232: 69-79.

Manschadi AM, Christopher J, Devoil P, Hammer GL 2006 The role of root architectural traits in adaptation of wheat to water-limited environments. Funct. Plant Biol. 33: 823-837.

Manschadi AM, Hammer GL, Christopher JT, deVoil P 2008 Genotypic variation in seedling root architectural traits and implications for drought adaptation in wheat (Triticum aestivum L.). Plant Soil 303: 115-129.

Massa GD, Gilroy S 2003 Touch and gravitropic set-point angle interact to modulate gravitropic growth in roots. Adv. Space Res. 31: 2195-2202.

Mosher PN, Miller MH 1972 Influence of soil temperature on geotropic response of corn roots (Zea mays L). Agron. J. 64: 459-462.

Nakamoto T 1994 Plagiogravitropism of maize roots. Plant Soil 165: 327-332.

Omori F, Mano Y 2007 QTL mapping of root angle in $\mathrm{F}_{2}$ populations from maize 'B73' $\times$ teosinte 'Zea luxurians'. Plant Root 1: 57-64.

Onderdon JJ, Ketcheso JW 1973 Effect of soil temperature on direction of corn root growth. Plant Soil 39: 177-186.

Pierret A, Kirby M, Moran C 2003 Simultaneous X-ray imaging of plant root growth and water uptake in thin-slab systems. Plant Soil 255: 361-373.

Ruta N, Liedgens M, Fracheboud Y, Stamp P, Hund A 2010 QTLs for the elongation of axile and lateral roots of maize in response to low water potential. Theor. Appl. Genet. 120: $621-631$.

Scott TK, Wilkins MB 1969 Auxin transport in roots. 4. Effects of light on IAA movement and geotropic responsiveness in Zea roots. Planta 87: 249-258.

Sheppard SC, Miller MH 1977 Temperature changes and geotropic reaction of radicle of Zea mays L. Plant Soil 47: 631-644.

Suzuki T, Fujii T 1978 Spectral dependence of light-induced geotropic response in Zea roots. Planta 142: 275-279.
Taramino G, Sauer M, Stauffer JL, Multani D, Niu XM, Sakai $\mathrm{H}$, Hochholdinger F 2007 The maize (Zea mays L.) RTCS gene encodes a LOB domain protein that is a key regulator of embryonic seminal and post-embryonic shoot-borne root initiation. Plant J. 50: 649-659.

Tardieu F, Pellerin S 1990 Trajectory of the nodal roots of maize in fields with low mechanical constraints. Plant Soil 124: 39-45.

Tardieu F, Pellerin S 1991 Influence of soil-temperature during root appearance on the trajectory of nodal roots of field-grown maize. Plant Soil 131: 207-214.

Trachsel S, Messmer R, Stamp P, A. H 2009 Mapping of QTLs for lateral and axile root growth of tropical maize. Theor. Appl. Genet. 119: 1413-1424.

Tsuji W, Inanaga S, Araki H, Morita S, An P, Sonobe K 2005 Development and distribution of root system in two grain sorghum cultivars originated from Sudan under drought stress. Plant Prod. Sci. 8: 553-562.

Van As H 2007 Intact plant MRI for the study of cell water relations, membrane permeability, cell-to-cell and long distance water transport. J. Exp. Bot. 58: 743-756.

Weaver JE 1925 Investigations on the root habits of plants. Am. J. Bot. 12: 502-509.

Woll K, Borsuk LA, Stransky H, Nettleton D, Schnable PS, Hochholdinger F 2005 Isolation, characterization, and pericycle-specific transcriptome analyses of the novel maize lateral and seminal root initiation mutant rum1. Plant Physiol. 139: 1255-1267.

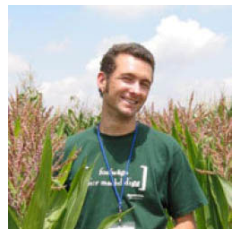

Dr. Andreas Hund's research interest is crop ecophysiology. His main focus is on the inheritance of root system architecture of maize and its adaptation to abiotic stresses. 